Water Science and Technology, Volume 72, Issue 10, 11 November 2015, pp1739-1746.

DOI: $10.2166 /$ wst.2015.394

The cost of a small MBR, WST-EM15827

\title{
The cost of a small membrane bioreactor
}

\author{
C.H. Lo ${ }^{1,2}$, E. McAdam ${ }^{1}$, and S. Judd*1,3 \\ ${ }^{1}$ Cranfield University, UK; ${ }^{2}$ Ecologix Technologies, Taiwan; ${ }^{3}$ Qatar University, Qatar. \\ *corresponding author, s.j.judd@cranfield.ac.uk; simon.judd@qu.edu.qa
}

\section{Abstract}

The individual cost contributions to the mechanical components of a small MBR $\left(100-2500 \mathrm{~m}^{3} / \mathrm{d}\right.$ flow capacity) are itemised and collated to generate overall capital and operating costs (CAPEX and OPEX) as a function of size. The outcomes are compared to those from previously published detailed cost studies provided for both very small containerised plants $\left(<40 \mathrm{~m}^{3} /\right.$ day capacity) and larger municipal plants $\left(2,200-19,000 \mathrm{~m}^{3} / \mathrm{d}\right)$.

Cost curves, as a function of flow capacity, determined for OPEX, CAPEX and NPV based on the heuristic data used indicate a logarithmic function for OPEX and a power-based one for the CAPEX. OPEX correlations were in good agreement quantitative agreement with those reported in the literature. Disparities in the calculated CAPEX trend with reported data was attributed to differences in assumptions concerning cost contributions. More reasonable agreement was obtained with the reported membrane separation component CAPEX data from published studies.

The heuristic approach taken appears appropriate for small-scale MBRs with minimal costs associated with installation. An overall relationship of NPV $=\left(a t^{b}\right) Q^{(-c \ln t+d)}$ was determined for the net present value where $a=1265, b=0.44, c=0.00385$ and $d=0.868$ according to the dataset employed for the analysis.

Keywords Membrane bioreactor; costs; CAPEX; OPEX; NPV

\section{Introduction}

Immersed membrane bioreactor (iMBR) plants may either be designed bespoke or be provided as a containerised technology with only relatively minor modifications on site. All large municipal plants are designed bespoke, and the costs incurred categorised as either part of the expenditure for operation (OPEX), the cost per treated product volume, or capital (CAPEX).

There is generally little information in the peer-reviewed literature on costs, but rather more on energy demand, a key contributor to water and wastewater treatment OPEX generally and aeration energy specifically. A number of MBR energy analyses from 2010 onwards (Verrecht et al, 2010; Liu et al, 2012; Krzeminski et al, 2012; Itokawa et al, 2014; Gabarron et al, 2014) have demonstrated the significance of operating at full capacity to maximise the flux and minimise the specific aeration demand $\left(S A D_{p}\right)$ - the ratio of the air demanded for membrane scouring to the permeate generated. Other studies have demonstrated the benefit of operating at low solids concentrations, which reduces energy for both mixing (Fenu et al, 2010) and biological (or process) aeration (Schaller et al, 2010; Henkel et al, 2011; Rodríguez et al, 2012). Energy-based papers have tended to illustrate the classic balance between OPEX and CAPEX (operating and capital expenditure) when considering TOTEX (total expenditure), particularly with reference to equalisation (Verrecht et al, 2010; Gabarrón et al, 2014) and waste sludge production and management (Schaller et al, 2010).

When considering TOTEX for the installation and operation over the entire life cycle of an installation other factors besides energy can contribute significantly to overall cost. In such cases it is appropriate to calculate the net present value (NPV), to account for the change in base utility and service costs, the value of the asset, and the value of money itself over the course of the plant life. The few reports in peer-reviewed literature of either TOTEX and/or NPV have tended to corroborate the importance of energy demand in determining OPEX. The energy demand appears to make up 27-34\% 
of the total OPEX for a large (19-48 MLD, or megalitres/day, flow capacity) municipal MBR according (De Carolis et al, 2007; Brepols et al, 2010; Young et al, 2013, 2014). Contributions from individual OPEX items can vary significantly according to assumptions made (Fig. 1) but the overall calculated 2015-corrected NPVs for the MBR for the analyses from these studies, based on a 19 MLD plant, are comparable at $\$ 60-80 \mathrm{~m}$.

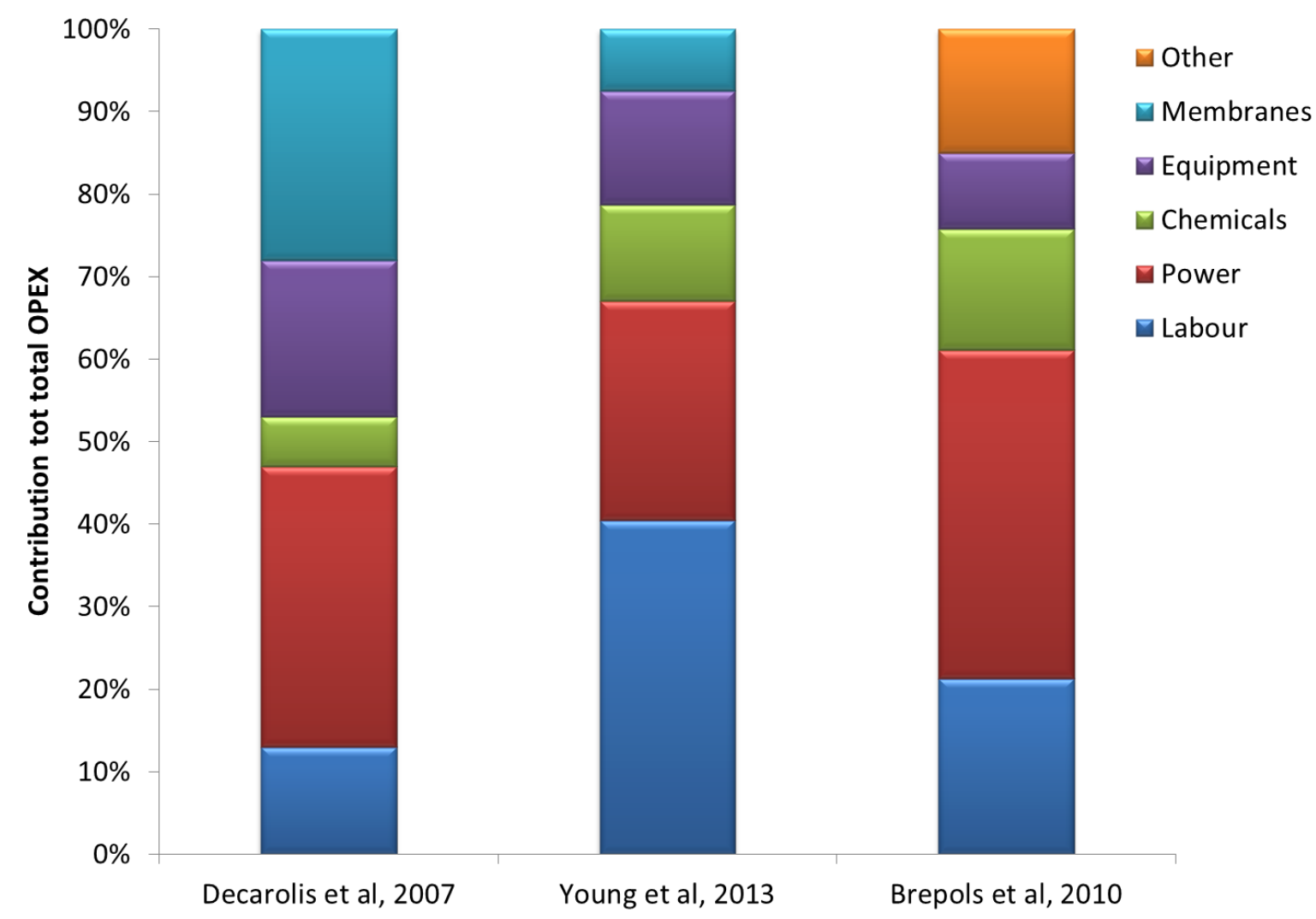

Figure 1. Breakdown of percentage OPEX contributions, published papers

Whilst these heuristic studies provide representative data, they are limited to specific installations/scenarios or else are aspecific in itemisation: cost contributors are not always consistently identified, and the impact of specific items varies according to the circumstances of the site. For example, waste sludge disposal is not identified as a single cost item in the reports by some authors, yet this item contributes 21\% of the OPEX at Nordkanal in Germany (Brepols et al, 2010); sludge management costs have been postulated as being comparable to aeration costs (Schaller et al, 2010). The Nordkanal analysis, on the other hand, excludes membrane replacement - which makes up 28\% of the OPEX in the DeCarolis et al study (Fig. 1). Moreover, these costs are all based on relatively large flows $\left(19,000-48,000 \mathrm{~m}^{3} / \mathrm{d}\right)$. There have been few full cost studies based on small-scale MBR systems, and those that have appeared have either been largely limited to OPEX (Verrecht et al, 2012) or have been based on small containerised systems (Fletcher et al, 2007). For small-scale MBRs, including containerised plants, the onus is on design simplicity and minimal manual intervention since the associated labour costs significantly add to TOTEX (Verrecht et al, 2012). Optimisation based on energy demand, as applied to large-scale systems, is less appropriate than system robustness in such cases.

It is of interest to assess the costs associated with the construction, installation and operation of a small to medium-sized bespoke flat sheet (FS) MBR typically applied to small municipal wastewater flows, since these make up the vast majority of MBR installations globally. This paper aims to provide a detailed and consistent cost analysis for such MBR installations focusing on the CAPEX of 
individually itemised components and OPEX determined on a consistent basis. Three different flow capacities so as to provide CAPEX and OPEX cost curves.

\section{Methodology}

The cost analysis proceeded by itemising each individual component (Table 1) of a standard treatment scheme (Fig. 2) for an MLE (modified Ludzack-Ettinger) process. All components were individually specified, ostensibly in terms of size, flow capacity and power rating, and priced from supplier information or based on proprietary data with reference to the geographical area of Southern China.

Table 1: MBR plant components and design basis

\begin{tabular}{|c|c|c|c|c|c|}
\hline \multicolumn{2}{|c|}{ Category } & Component $(s)$ & $I D$ & Description/purpose & Note \\
\hline \multirow{9}{*}{\multicolumn{2}{|c|}{ Tanks }} & Raw water & $\mathrm{T} 1$ & Storage tank for inlet wastewater & \\
\hline & & Primary sedimentation & $\mathrm{T} 2$ & Removal of gross, settleable solids & 1 \\
\hline & & Equalisation (EQ) & T3 & Equalisation of flow & 2 \\
\hline & & Anoxic $(A x)$ & $\mathrm{T} 4$ & Denitrification & 3 \\
\hline & & Aeration (Ae) & T5 & Nitrification and biological oxidation & 3 \\
\hline & & Membrane & T6 & Membrane separation & 3 \\
\hline & & Treated water & $\mathrm{T} 7$ & Storage of permeate water & \\
\hline & & Sludge & $\mathrm{T} 8$ & Storage of wasted sludge & \\
\hline & & Chemicals storage & $\mathrm{T} 9,10$ & & \\
\hline \multirow{6}{*}{\multicolumn{2}{|c|}{ Pumps }} & Settled sludge transfer & $\mathrm{P} 1$ & Submerged, settled sludge to sludge storage tank & 4 \\
\hline & & Feed & $\mathrm{P} 2$ & EQ tank through rotary screen & 4 \\
\hline & & Permeate & $\mathrm{P} 3$ & Self-priming, membrane suction filtration & 4 \\
\hline & & Sludge return/discharge & $\mathrm{P} 4$ & Submerged, sludge recirculation and excess & 5 \\
\hline & & Sludge transfer & P5 & WAS to dewatering & 6 \\
\hline & & Chemicals & P6,7 & Cleaning chemicals transfer to membrane, $\mathrm{x} 2$ & 7 \\
\hline \multirow{2}{*}{\multicolumn{2}{|c|}{ Blower }} & Process & B1 & Biological process aeration & 8 \\
\hline & & Membrane & B2 & Membrane scouring & 9 \\
\hline \multirow{2}{*}{\multicolumn{2}{|c|}{ Mixer }} & EQ tank mixer & $\mathrm{X} 1$ & High speed, equalisation tank & \\
\hline & & Ax tank mixer & $\mathrm{X} 2$ & Low speed, anoxic tank & \\
\hline \multirow{4}{*}{\multicolumn{2}{|c|}{$\begin{array}{l}\text { Screen } \\
\text { Membrane } \\
\text { Diffusers }\end{array}$}} & Rotary screen & $\mathrm{S} 1$ & Fine screening of feed & \\
\hline & & Membrane module & M1 & FS membrane plus frame with built-in aerator & 10 \\
\hline & & Fine bubble diffuser & D1 & Process aeration & \\
\hline & & Coarse bubble diffuser & D2 & Membrane aeration & \\
\hline \multicolumn{6}{|c|}{$1 \quad 0.48-0.58 \mathrm{~h}$ hydraulic residence time (HRT) } \\
\hline \multicolumn{6}{|c|}{$2 \quad 6.4-6.5$ h HRT } \\
\hline \multicolumn{6}{|c|}{$3 \quad 8.1-8.2 \mathrm{~h} \mathrm{HRT}$ total } \\
\hline \multicolumn{6}{|c|}{$4 \quad$ Flow capacity of $125 \%$ of feed flow } \\
\hline \multicolumn{6}{|c|}{ Flow capacity of $250 \%$ of feed flow $($ Recycle ratio $=2.5 Q)$} \\
\hline \multicolumn{6}{|c|}{6 Flow capacity of $10-12 \%$ of feed flow } \\
\hline \multicolumn{6}{|c|}{$7 \quad 10 \mathrm{~L} / \mathrm{min}$, applied weekly for $120 \mathrm{mins}$ total } \\
\hline \multicolumn{6}{|c|}{ Process aeration rate $S A D_{p, b i o}=11.5 \mathrm{Nm}^{3} / \mathrm{m}^{3} ;$ aeration energy $=0.017-0.024 \mathrm{kWh} / \mathrm{Nm}^{3}$} \\
\hline 9 & \multicolumn{5}{|c|}{ Membrane air scour rate $S A D_{p}=26 \mathrm{Nm}^{3} / \mathrm{m}^{3} ;$ aeration energy $=0.015-0.022 \mathrm{kWh} / \mathrm{Nm}^{3}$} \\
\hline 10 & \multicolumn{5}{|c|}{ Flux of $0.5 \mathrm{~m} / \mathrm{d}$} \\
\hline
\end{tabular}

The basis of the design is included in the Table 1 footnotes, with other key cost assumptions provided in Table 2. A design value of $26 \mathrm{Nm}^{3}$ air per $\mathrm{m}^{3}$ permeate for membrane air scouring $\left(S A D_{p}\right)$ was used, a significantly higher value than those normally associated with large-scale wastewater treatment $\left(S A D_{p} \sim 10 \mathrm{Nm}^{3} / \mathrm{m}^{3}\right.$, Judd (2014)). The high $S A D_{p}$ required for the smaller plants considered in the current analysis reflects a more conservative design required to minimise the risk of process upset and unscheduled manual intervention. The selected design process aeration rate (for sustaining biological treatment) of $11.5 \mathrm{Nm}^{3} / \mathrm{m}^{3}$ assumes intermittent operation of the process blower for moderate strength municipal wastewaters, based on a dissolved oxygen concentration set-point concentration of $1-2 \mathrm{mg} / \mathrm{L}$. 


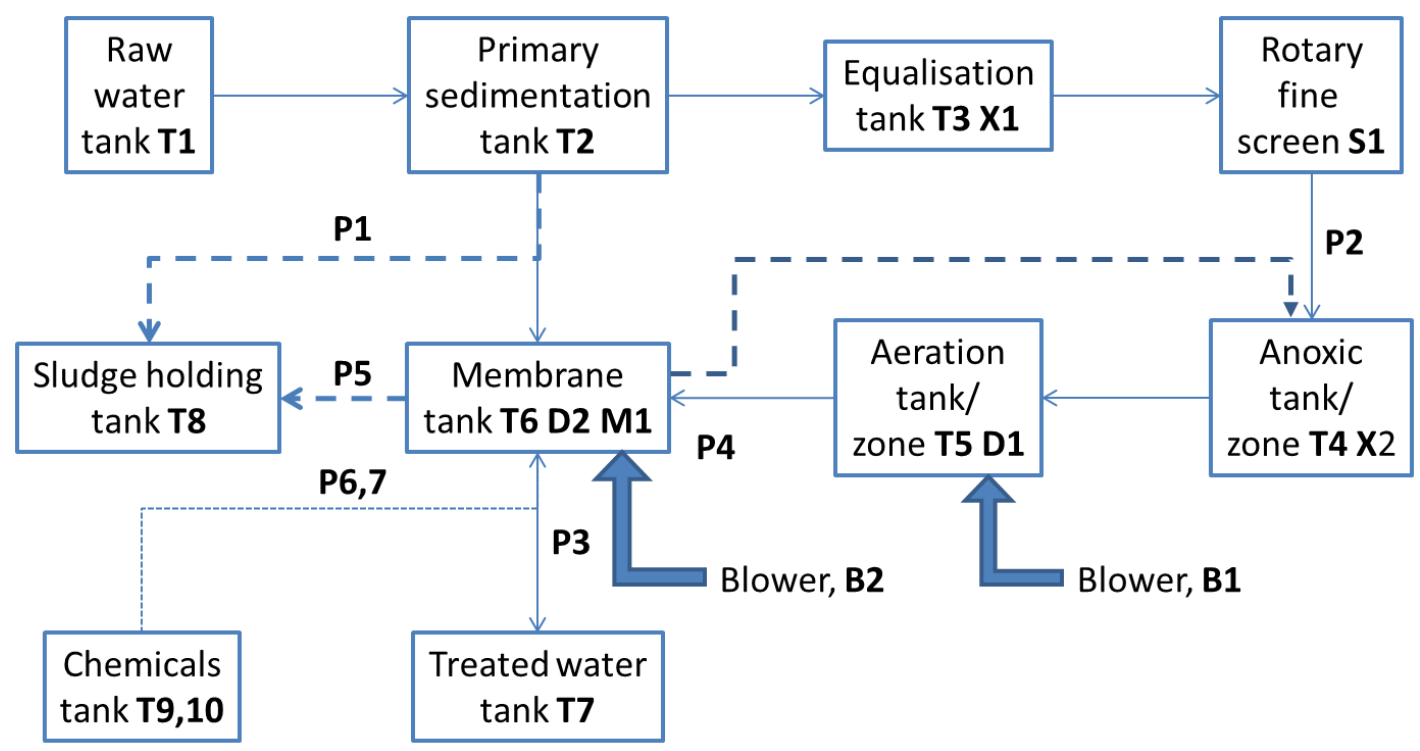

Figure 2. Plant schematic, see Table 1 for codes

Table 2: Key cost components

\begin{tabular}{|c|c|c|c|c|c|}
\hline Cost component & \multicolumn{5}{|c|}{ Value (range) } \\
\hline Electrical energy cost & $L_{E}$ & $\$ / \mathrm{kWh}$ & 0.1 & & \\
\hline Membrane cost & $L_{M}$ & $\$ / \mathrm{m}^{2}$ & 79.16 & & \\
\hline Chemicals cost & $L_{C}$ & $\$ / \mathrm{m}^{3}$ & 0.0091 & & \\
\hline Membrane life & $t_{m e m}$ & $\mathrm{y}$ & 5 & & \\
\hline Plant life & $t$ & $\mathrm{y}$ & $5-20$ & & \\
\hline Margin, proportion of equipment purchase costs & & & $15 \%$ & & \\
\hline Assembly, proportion of CAPEX & & & $20 \%$ & & \\
\hline Discount rate & & & $5 \%$ & & \\
\hline \multicolumn{6}{|l|}{ Labour } \\
\hline$\overline{\text { Annual salary of operator/maintenance engineer }}$ & & $\$ / y$ & 15,167 & & \\
\hline $\mathrm{O} / \mathrm{h}$ on salary (incl. employer tax \& pension contrib.) & & & $30 \%$ & & \\
\hline No. working hours per year & & $\mathrm{hrs} / \mathrm{y}$ & 2,700 & & \\
\hline Proportion of working day spent maintaining MBR & & & $15 \%$ & & \\
\hline Flow, $Q$ & & $\mathrm{~m}^{3} / \mathrm{d}$ & 100 & 500 & 2500 \\
\hline Number of staff & & & 1 & 2 & 5 \\
\hline Labour cost & $L_{L}$ & $\$ / \mathrm{m}^{3}$ & 0.061 & 0.024 & 0.012 \\
\hline Contribution of labour costs to total & & & $14.0 \%$ & $5.6 \%$ & $2.8 \%$ \\
\hline
\end{tabular}

Three different plant capacities were considered: 100, 500 and $2500 \mathrm{~m}^{3} / \mathrm{d}$. Specifications for the categorised components listed in Table 1 (tanks T1-T8, pumps P1-P7, blowers B1 \& B2, mixers X1 \& $\mathrm{X} 2$, screen S1, membranes M1, and diffusers D1) were used to obtain itemised costs provided by regional suppliers in Taiwan and Southern China. Costs within each category were then summed for further analysis of CAPEX trends. The OPEX in $\$$ per $\mathrm{m}^{3}$ permeate was determined according to the combined cost of energy demand, critical component replacement, chemicals consumption, waste management/disposal and labour (Judd, 2014):

$$
\mathrm{OPEX}=L_{E} E_{\text {tot }}+365 L_{M} /\left(J t_{m e m}\right)+L_{C}+L_{W}+L_{L}
$$

where $L_{E}$ is the cost of electrical energy in $\$ / \mathrm{kWh}, L_{M}$ the membrane cost per $\mathrm{m}^{2}$ membrane area, $J$ the flux in $\mathrm{m} / \mathrm{d}$ and $t_{m e m}$ the membrane life in years. $L_{C}, L_{W}$ and $L_{L}$ represent the specific costs per $\mathrm{m}^{3}$ treated water for chemicals consumption, waste disposal and labour, with all these other than waste disposal included in the current analysis. The total specific energy demand $E_{t o t}$ in $\mathrm{kWh} / \mathrm{m}^{3}$ is provided by the sum of the power consumption rating $W$ in $\mathrm{kW}$ of the individual component, the (estimated) fractional operational period $\tau$ (hours per day of operation divided by 24) and the permeate flow $Q_{p}$ in $\mathrm{m}^{3} / \mathrm{d}$ : 


$$
E_{\text {tot }}=\sum \frac{24 W \tau}{Q_{p}}
$$

CAPEX and OPEX can be combined to estimate the averaged net present value (NPV) according to the simplified relationship (Verrecht et al, 2010):

$$
\mathrm{NPV}=-\mathrm{OPEX} \frac{1-(1+i)^{-t}}{i}-\mathrm{CAPEX}
$$

where $i$ the annual discount rate and $t$ the amortisation period (or plant life) in years. The above equation allows for inflation and assumes zero residual value of the plant at the end of its life.

All costs for the literature data was converted to US \$ based on annual retail price index data.

\section{$3 \quad$ Results and discussion}

The outcomes of the CAPEX analysis reveal that 70-94\% of the capital equipment cost is taken up by the membranes and diffusers, the proportion increasing with plant size (Fig. 3(a)). A consideration of energy demand reveals the proportional energy contribution of screening and stirring to decrease with size (Fig. 3b). This arises from the practical limitation of sizing these items for the smallest installation: the same mixer and screen is fitted for both the 100 and $500 \mathrm{~m}^{3} / \mathrm{d}$ plants, such that the equipment for the smallest plant is oversized.
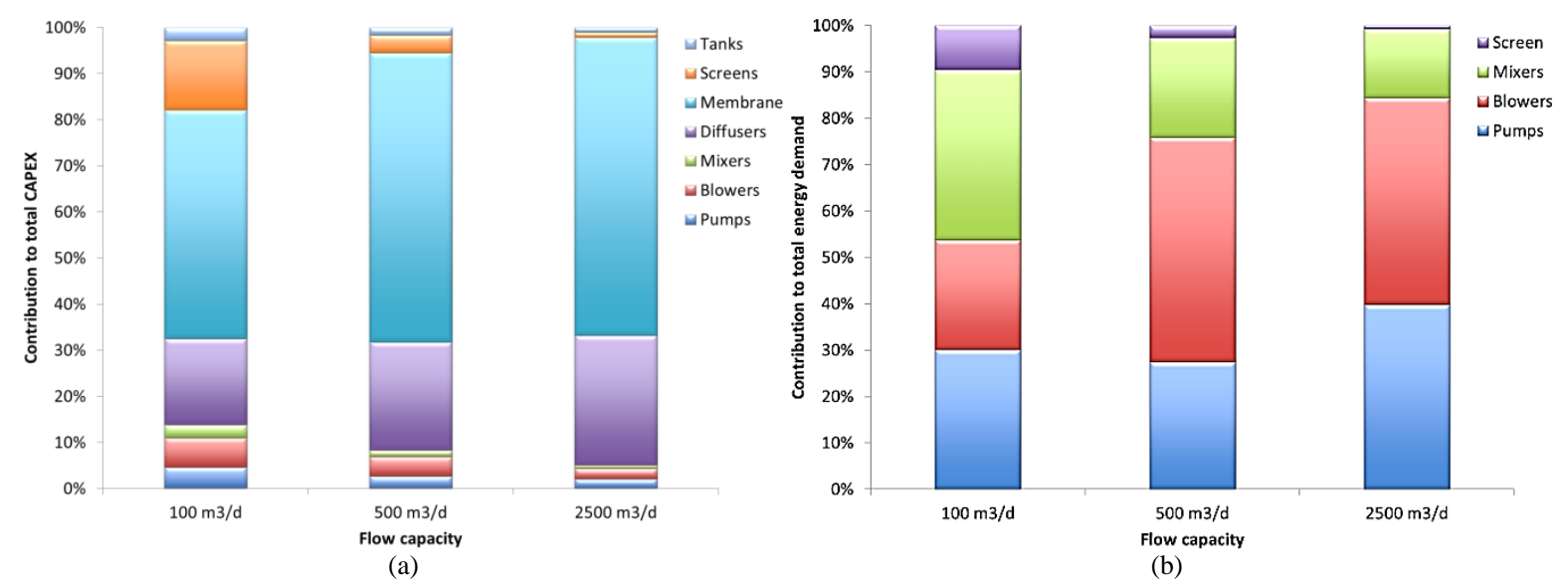

Figure 3. (a) Capital cost, and (b) Energy demand contributions at the three different flow capacities

Correlations for absolute costs (Fig. 4) reveal the expected decrease in specific cost (cost per unit product water) with plant capacity. According to these data, based on the available cost data and conditions outlined in Tables 1 and 2, cost trends follow the relationships with flow capacity $Q$ :

$$
\begin{array}{lr}
\text { CAPEX }=1060 Q^{0.872} & 4 \\
\text { OPEX }=-0.0509 \ln Q+0.664 & 5
\end{array}
$$

The exponent value for the CAPEX equation (Equation 4) approaches unity, reflecting the expected low economy of scale associated with a modular treatment process and the dominant contribution of the membrane assembly to the overall equipment costs. The decrease in OPEX with capacity arises primarily from the oversizing of components at the smallest scales. 


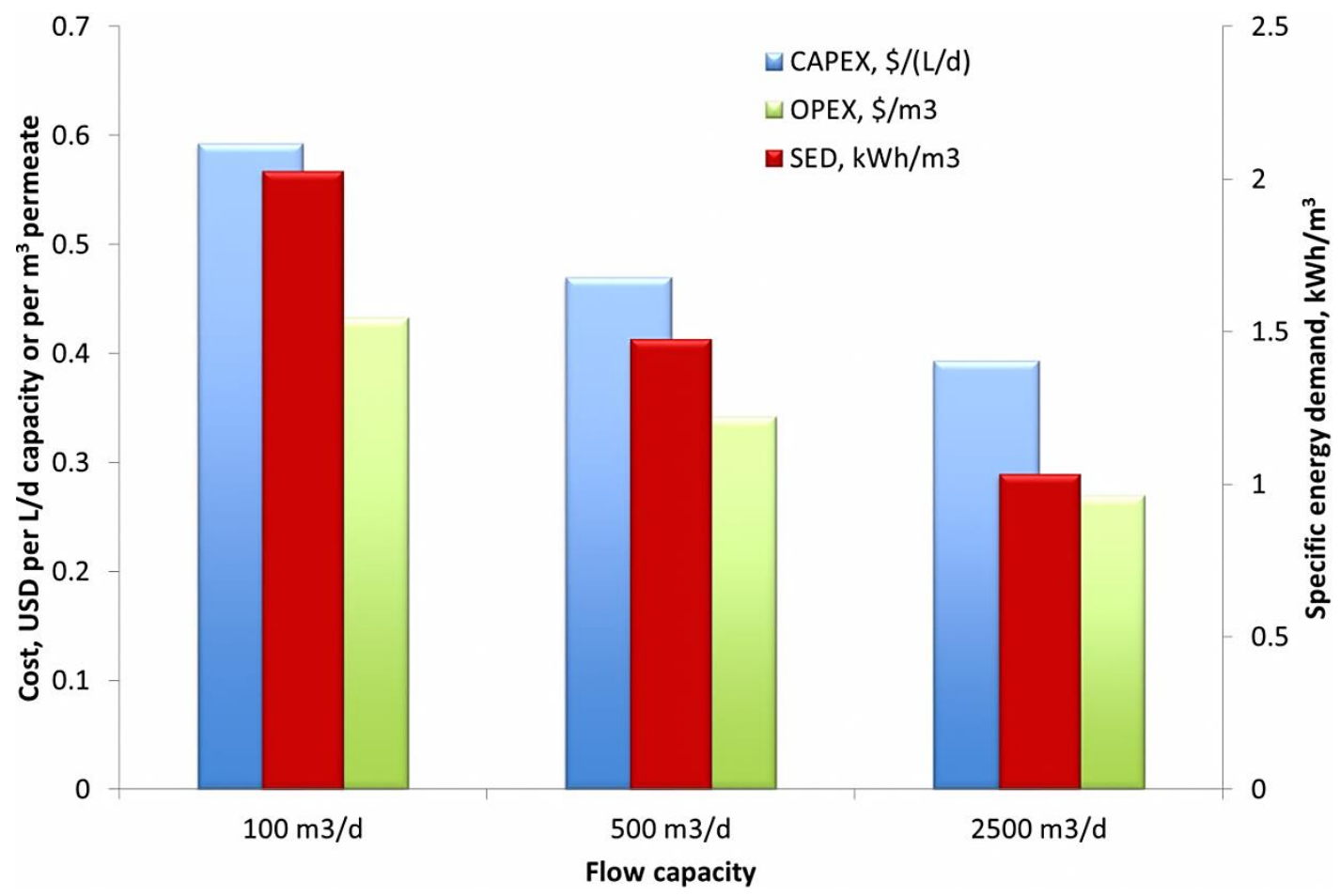

Figure 4. Cost and energy data at the three different flow capacities

Extrapolating these trends to the higher flows on which analyses conducted by previous authors were based permits comparison with the mean reported published data (Fig. 5). Data from such studies relate to the membrane and ancillary capital equipment component specifically, this being considered most pertinent to the current study. Results show the OPEX trend to be in good agreement with the mean data from the identified studies. The sharp increase in OPEX at low flows reflects trends reported by other authors (Fletcher et al, 2007; Brepols et al, 2010; Verrecht et al, 2012). The extent of this increase is highly dependent on values assigned to key contributors such as peak loading factor, electrical and labour costs, and the degree of manual intervention.

Cost estimates at low flows are challenged by variations in the degree of contingency assumed. The peak loading factors and the associated oversizing demanded at low flows have led to recorded mean SED values of between $1.8 \mathrm{kWh} / \mathrm{m}^{3}$ (Brepols et al, 2010) to as high as $10 \mathrm{kWh} / \mathrm{m}^{3}$ (Verrecht et al, 2012; Itokawa et al, 2014). For the Verrecht et al study, labour costs were calculated to contribute more than half the operating cost. Moreover, a study of 84 municipal MBR installations between 2,000 and $22,000 \mathrm{~m}^{3} / \mathrm{d}$ capacity revealed the number of FTE (full time equivalent) operators per 1000 $\mathrm{m}^{3} / \mathrm{d}$ of treated wastewater to vary between 0.3 and 2.5 (Mathis, 2011), the ratio increasing with decreasing flow capacity. The corresponding range of values adopted for the current study is 0.3 FTE per $1000 \mathrm{~m}^{3} / \mathrm{d}$ at the highest flow considered to $1.5 \mathrm{FTE}$ at the lowest.

OPEX estimates are subject to increased imprecision at low flows $\left(<500 \mathrm{~m}^{3} / \mathrm{d}\right)$. However, given a consistent set of assumed values for the key OPEX components in Equation 1, the trend above 500 $\mathrm{m}^{3} / \mathrm{d}$ flow capacity appears to be reasonably representative. Trends in CAPEX, on the other hand, are more vagarious - primarily due to the different scope and itemisation of costs in published studies combined with errors introduced by overly simplistic normalisation (Newnan et al, 2013). The projected CAPEX of a $19,000 \mathrm{~m}^{3} / \mathrm{d}$ plant is around $\$ 6 \mathrm{~m}$ according to the current study. This figure is $86 \%$ of the mean membrane equipment cost determined by DeCarolis et al (2007), and around half that of the corresponding cost calculated by Young et al (2013). The only other cost study detailing individual components and based on low flows, in this case employing containerised MBR systems, reported equivalent CAPEX figures (in 2015 \$) of around 49-62k USD equipment costs at the maximum flow of $40 \mathrm{~m}^{3} / \mathrm{d}$ considered in their study (Fletcher et al, 2007). This is comparable to the CAPEX of $\$ 59 \mathrm{k}$ determined for the smallest plant of $100 \mathrm{~m}^{3} / \mathrm{d}$ considered in the current study. 
Moreover, the CAPEX figure for the membrane component of the cost quoted by Brepols et al (2010) for a 10,000 population equivalent plant (assumed to equate to a flow of 2,500 $\mathrm{m}^{3} / \mathrm{d}$ ) was slightly lower than the projected value based on Equation 3 (Fig. 5).

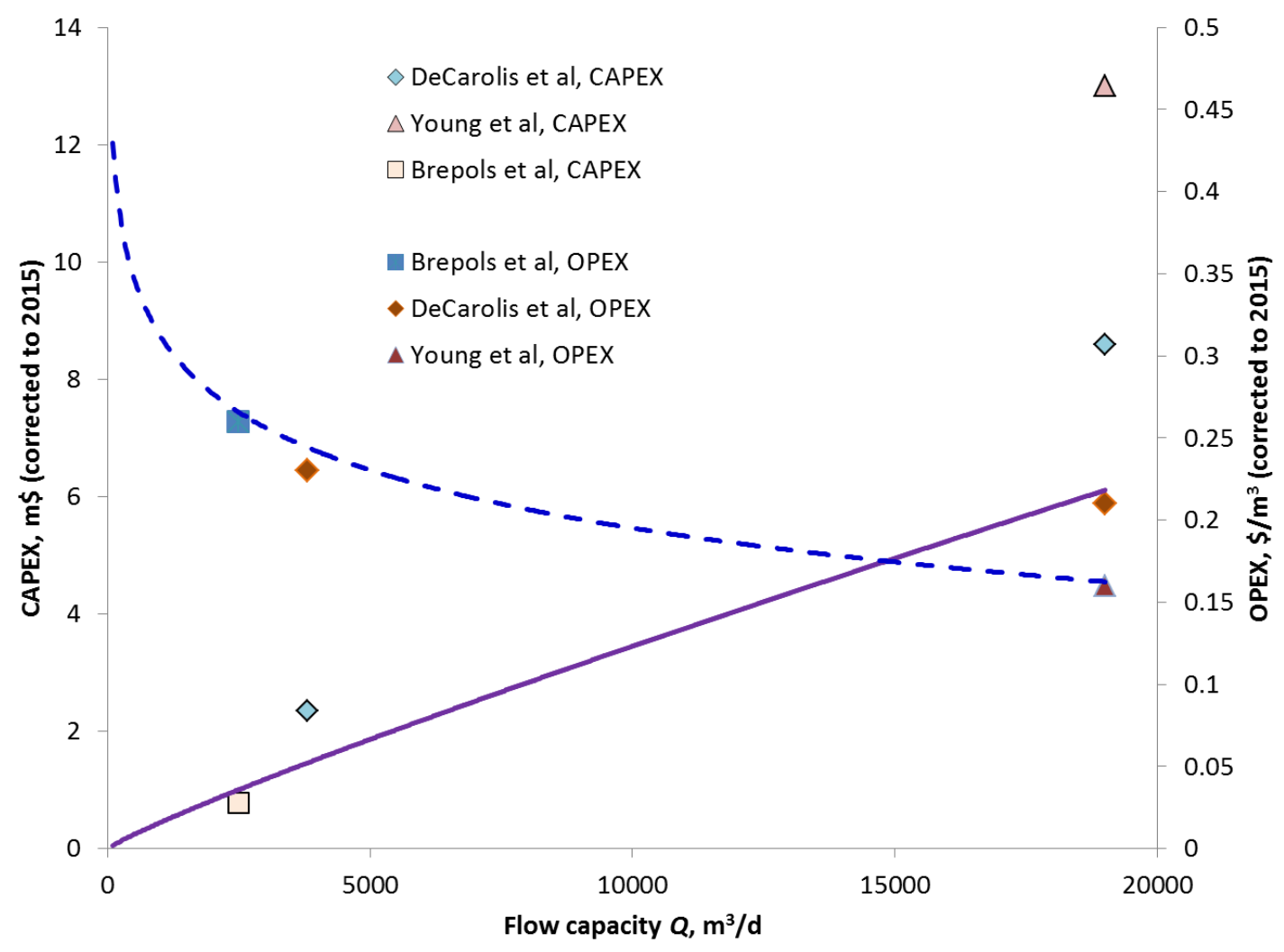

Figure 5. Cost trends (Equations 3 and 4) against reported data for MBR OPEX and membrane component CAPEX

The mean NPV (Fig. 6a) determined at each flow capacity follows the general trend with plant life $t$ (with an $\mathrm{R}^{2}$ value of $>0.985$ in all cases):

$$
\mathrm{NPV}=a t^{b}
$$

where $a$ and $b$ are empirical constants and the exponent $b$ varies between 0.419 , for the largest plant, and 0.406 for the smallest. Plotting NPV vs. Q (in $\mathrm{m}^{3} / \mathrm{d}$ ) at plant life values between 1 and 20 years generates a series of cost curves (Fig. 6b) following the same exponential form as above (i.e. NPV = $m Q^{n}$ ). Simple curve fitting of the coefficient and exponent values for these cost curves provides the following overall relationship for NPV as a function of flow capacity $Q$ and plant life $t$ in years:

$$
\text { NPV, } \$=\left(1265 t^{0.44}\right) Q^{(-0.00385 \ln t+0.868)}
$$

Thus, according to the cost data in Table 2 and based on the generalised OPEX equation (Equation 1):

a) the plant NPV follows a power law relationship with both flow and plant life;

b) the coefficient of the power law relationship between NPV and flow $Q$ follows an approximate square root relationship with plant life $t$; and

c) the exponent value for the above NPV vs. $Q$ equation decays logarithmically with plant life.

There appear to have been no cost functions previously published for MBR installations. However, Equation 7 is consistent with the general expectation of decreased specific costs (cost per unit volume water treated) with both flow capacity and plant life. The quantitative NPV of $\$ 22 \mathrm{~m}$ USD determined at $\mathrm{Q}=19,000 \mathrm{~m}^{3} / \mathrm{d}$ and a $20 \mathrm{y}$ plant life is considerably lower than the $\$ 55-80 \mathrm{~m}$ range calculated by 
previous authors for the same conditions since it is ostensibly limited to the membrane and equipment component alone. Installation and other site-specific costs outside of those directly relating to capital equipment (e.g. civils, mechanical and electrical) make up a more significant proportion of the costs for large-scale municipal installations.

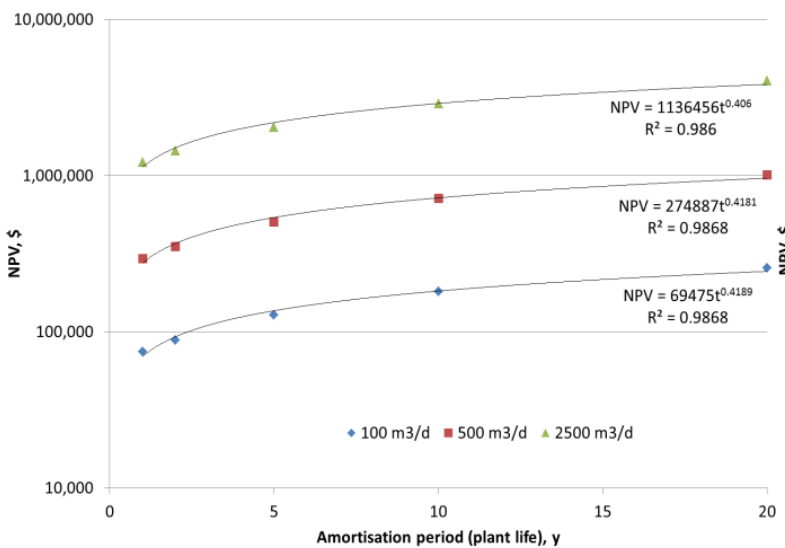

(a)

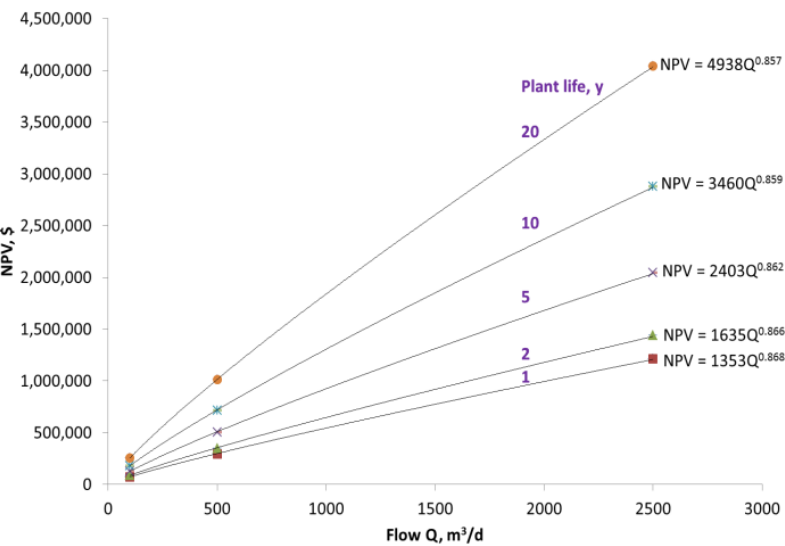

(b)

Figure 6. NPV vs (a) plant life at the three different flow capacities, and (b) flow capacity at five different plant life values

\section{$4 \quad$ Conclusions}

An analysis of the cost of a small membrane bioreactor, 500-2500 $\mathrm{m}^{3} / \mathrm{h}$ capacity and based on flat sheet membrane technology, has been conducted based on individual itemisation encompassing both purchase cost and energy demand. The analysis provides a cost curve, the cost as a function of flow and plant life, and reveals:

- CAPEX (capital expenditure) to increase with flow $Q$ according to a power law relationship with an exponent value of 0.87

- OPEX (operating expenditure per $\mathrm{m}^{3}$ treated water) to decrease logarithmically with flow, with an intercept of $\sim 0.45$.

- NPV (net present value in \$) to increase with flow $Q$ in $\mathrm{m}^{3} / \mathrm{d}$ and plant life $t$ in years according to the equation:

$$
\mathrm{NPV}=a t^{b} Q^{(-c \ln t+d)}
$$

where, according to the dataset employed, $a=1265, b=0.44, c=0.0039$ and $d=0.87$.

The trend determined for OPEX was in good agreement with that reported from three other studies of larger-scale plants. CAPEX and NPV were both significantly lower, however, since these parameters are largely associated with the MBR technology per se rather than ancillary installation costs (such as civils, mechanical and electrical, and miscellaneous site work). It is concluded that this heuristic approach is appropriate to small-scale installations $\left(\$ 5,000 \mathrm{~m}^{3} / \mathrm{d}\right)$ and/or the equipment component of larger MBRs, but requires modification for larger-scale installations.

\section{Acknowledgements}

The authors are grateful to Ecologix Technologies Asia Pacific, Inc., Taiwan, for providing technical and cost data for this article.

\section{References}

Brepols, B, Schäfer, H., and Engelhardt, N., 2010. Considerations on the design and financial feasibility of full-scale membrane bioreactors for municipal applications. Water Sci. Technol. 61(10), 2461-2468. 
DeCarolis, J., Adham, S., Pearce, W.R., Hirani, Z., Lacy, S., Stephenson, R., 2007. Cost trends of MBR systems for municipal wastewater treatment, Proceedings of the Water Environment Federation, 13-17 October, San Diego, 3407-3418.

Fenu, A., De Wilde, W., Gaertner, M., Weemaes, M., de Gueldre, G., and Van De Steene, B., 2012. Elaborating the membrane life concept in a full scale hollow-fibers MBR. J. Membrane Sci. 421-422, 349354.

Fletcher, H., Mackley, T., and Judd, S., 2007. The cost of a package plant membrane bioreactor, Water Res. 41, 2627-2635.

Gabarrón, S., Ferrero, G., Dalmau, M., Comas, J., and Rodriguez-Roda, I., 2014. Assessment of energysaving strategies and operational costs in full-scale membrane bioreactors. J. Environ. Management 134, 814.

Henkel, J., Cornel, P., and Wagner, M., 2011. Oxygen transfer in activated sludge - new insights and potentials for cost saving. Water Sci. Technol. 63(2), 3034-3038.

Itokawa, H., Tsuji, K., Yamashita, K. and, Hashimoto, T., 2014. Design and operating experiences of fullscale municipal membrane bioreactors in Japan. Water Sci. Technol. 69(5), 1088-1093.

Judd, S. (2014). Industrial MBRs, Judd and Judd Ltd. (Cranfield, UK).

Krzeminski P., van der Graaf J.H.J.M and van Lier J.B., 2012. Specific energy consumption of membrane bioreactor (MBR) for sewage treatment. Water Sci. Technol. 65, 380-392

Lawrence, S., and Codiane, B., 2014. SBR vs MBR - A tale of two wastewater plants. Technical Session, WEFTEC, 28 Sep - 1 Oct, New Orleans.

Liu, H. Y., Freeman, B., Sunano, S., Munehiro, N., Bartels, C. and Oda Y., 2012. Stable operation of MBR under high permeate flux. Water Practice Technol. 7(4) 1-7.

Mathis, K., MBRs for cost-effective wastewater treatment. Water and Waste Digest, 14 Oct 2011

Newnan, D.G., Lavelle, J.P., and Eschenbach, T.G., 2013. Engineering Economic Analysis, 12 ${ }^{\text {th }}$ ed. Oxford University Press, USA.

Rodríguez, F.A., Reboleiro-Rivas, P., Osorioa, F., Martínez-Toledo, M.V., Hontoria, E., and Poyatos, J.M., 2012. Influence of mixed liquid suspended solids and hydraulic retention time on oxygen transfer efficiency and viscosity in a submerged membrane bioreactor using pure oxygen to supply aerobic conditions. Biochem Engng. J. 60, 135-141.

Schaller, J., Drews, A., Kraume, M., 2011. Development of a cost model for membrane bioreactors including sludge handling costs. Desalination and Water Treatment 18, 315-320.

Verrecht, B., James, C., Germain, E., Birks, R., Barugh, A., Pearce, P., and Judd, S. (2012). Economical evaluation and operating experiences of a small scale MBR for non-potable reuse, J. Environ. Eng. 138, 594.

Verrecht, B., Nopens, I., Maere, T., Brepols, C., and Judd, S., 2010. The cost of a large-scale hollow fibre MBR, Water Research 44, 5274-5283.

Young, T., Smoot, S., Peeters, J., Côté, P., 2013. When does building an MBR make sense? How variations of local construction and operating cost parameters impact overall project economics, Proc. Water Environment Federation 8, 6354-6365.

Young, T., Smoot, S., Peeters, J., J., Côté, P., 2014. Cost-effectiveness of membrane bioreactors treatment system for low-level phosphorus reduction from municipal wastewater, Water Practice Technol. 9(3) 316323. 